\title{
Language Policy and Its Consequences on Sindhi Language Teaching in Sindh, Pakistan
}

\author{
Habibullah Pathan ${ }^{1}$, Syed Waqar Ali Shah ${ }^{1}$, Shoukat Ali Lohar ${ }^{1}$, Ali Raza Khoso ${ }^{1} \&$ Sadia Memon $^{1}$ \\ ${ }^{1}$ Mehran university of Engineering \& Technology, Jamshoro, Sindh, Pakistan \\ Correspondence: Syed Waqar Ali Shah, Mehran University of Engineering \& Technology, Jamshoro, Sindh, \\ Pakistan. E-mail: waqar.shah@faculty.muet.edu.pk
}

\author{
Received: April 15, 2018 Accepted: May 4, 2018 Online Published: May 23, 2018 \\ doi:10.5539/ijel.v8n5p135 URL: https://doi.org/10.5539/ijel.v8n5p135
}

\begin{abstract}
This paper examines the language teaching policy in Pakistan and its consequences on Sindhi language in Sindh province. The paper argues that such language policy has attempted to marginalize other local and indigenous languages of the country in general and Sindhi language in particular. Politics is actively engaged in determining the status of languages in the country. English and Urdu being the languages of the dominant social group, that is, the ruling elite in the country enjoy status of official and national languages respectively whereas languages of the marginalized group are excluded from the domain of education, literacy and power. The paper, thus, draws attention of the language policy makers to linguistic human rights and argues that all the languages should be treated equally. Education being inborn right of human being should be acquired in one's own mother tongue; this is the only solution to cope with present and future challenges in Pakistani educational system.
\end{abstract}

Keywords: language policy, politics, language rights, Sindhi language, Pakistan

\section{Introduction}

Language policies in Pakistan have seen various shifts due to certain political agenda. The language in the country is explicitly a political issue. The status of a language is decided by the power and the ruling elite. Whitley's (1993) claim that language policy decisions are taken on 'political grounds and always follow certain ideologies. Thus, language policy is not merely a linguistic issue. It needs to be seen in political perspective (Rahman, 2007, 2010; Mustafa, 2011; Manan et al., 2017). Since inception, Urdu and English have been viewed as symbols of prestige, honor and instrumental functionalities like education and jobs (Shah \& Pathan, 2016; Pathan, 2012). Rahman (1998) states that Urdu language has come to have acquired a symbolic value in the country for two reasons: political and psychological. The ruling elite in Pakistan have used 'Urdu' and 'Islam' as powerful tools to preserve national integration and identity while ignoring indigenous languages. This position of Urdu came under attack by the ethno-nationalists who viewed their language the most important heritage to them ever. They saw such state policy as discriminatory forces against the indigenous people and their languages.

The psychological dimension of this policy allowed one or two culture (s) to rule over the rest of the indigenous cultures which did not receive any positive welcome from the ethnic groups. Language and culture cannot be separated from each other. Jaspel (2009) says that language has two major goals: communication and constructing one's identity. Winona Laduke quoted in (Errington, 2008) says that languages have deeper relation with human beings and their lands. All human teachings are preserved in their languages; if a language is lost everything is lost. The loss of a language is, indeed, a loss to human cultural, philosophical, intellectual and spiritual experiences. The ethno-nationalists considers this view of language and thus, challenges the position of Urdu and English languages which are the killer languages in a sense that these languages marginalize people's indigenous languages and cultures. Skuttnab-Kangas (cited in Phillipson, 1992) calls this phenomenon 'genocide'.

As a result of state's hegemonic language policies, Sindhi language has started to lose its status. It has started receiving very insignificant value by most people in urban Sindh. The teaching of Sindhi is heavily influenced by the state's policies; many private schools in Sindh have stopped teaching Sindhi language to students whose mother tongue is Sindhi. This is due to the fact that Sindhi language does not have currency value in Sindh; it is not a major requirement of jobs, education, judiciary or other domains of power. The current study, therefore, investigates the language policies in Pakistan since its beginning and their consequences on Sindhi language 
teaching in Sindh - the province of Pakistan. It further suggests that languages have rights which are to be taken into account at any cost. The study carefully analyses the last three years ASER Reports on Education in Pakistan along with the national education policy (2009).

\subsection{Problem of the Study}

As a result of hegemonic policy of the state, many private schools in Sindh, Pakistan either do not teach Sindhi language or give a less focus. Consequently, very low competency in Sindhi language has been observed. Thus, linguistic human rights (LHRs) are at disadvantage in Sindh, Pakistan. Educational inequality in terms of language is propagated.

\subsection{Questions of the Study}

The study addresses the following questions:

1) What are the extra-linguistic factors involved in status planning of any language?

2) What are the consequences of State Policy of language on Sindhi Language Teaching in Sindh, Pakistan?

\section{Literature Review}

This section of the paper highlights a brief overview of language policy in Pakistan and its consequence on other tongues in the country. At the time of independence, Pakistan like other ex-colonies was faced the problem of developing a language policy. It is due to the fact that the country has different linguistic and ethnic groups and they were competing for their languages to be recognized as national languages. The dominant languages at that time were Bengali and Urdu: the former in terms of population forming the $54.6 \%$ of total population of Pakistan; the latter in terms of 'ruling elite' which formed about 7\% percent of total population. The both languages stood in line competing for acquiring national language status. Mahboob in Obeng et al. (2002) maintains that the prominent leader like Muhammad Ali Jinnah and Liaquat Ali Khan supported Urdu as national language. Mahboob quotes Jinnah's speech made in Bengal who says that '.. it is for you, the people of this province, to decide what shall be the language of your province. But let make it clear to you that the State Language of Pakistan is going to be Urdu and no other language. Anyone who tries to mislead you is really the enemy of Pakistan.' Mahboob (ibid) mentions that this speech received very strong reaction of Bengalis who protested against Urdu to be the only national language in the country. This created a division: East \& West Pakistan.

Mahboob (2002, p. 21) reports that it was, however, not possible for Pakistan to make Urdu the only official/national language due to lack of materials in Urdu (corpus planning). This gave Pakistan three language structure in order to avoid any discrepancy in running government smoothly. Thus, English language was recognized as an official language of the country. Besides Urdu as national and English as official language the provinces were allowed to recognize their language as provincial language. This three language structure, according to the present study was again in disfavor of other/regional ethnic groups whose language being in minority lacked the market-value. Rahman (1996) maintains that in order to create Pakistani-Muslim identity, the indigenous languages were marginalized in the country.

With the change in political structure, the language policies also varied to some extent. The 1958 witnessed the first martial law government in Pakistan imposed by Ayub Khan, the military ruler. He was pro-English and considered to be the language of modernity. Ayub Khan wanted all qualified personnel to acquire competence in English language. To achieve this target, all the training for military officers was in English and cadets were not allowed to use ethnic languages as noted by Mahboob (2002, p. 22). Rehman (1996) says that Ayub Khan in order to establish strong central government welded four provinces into one unit as he thought that the provincial boundaries were actually the creation of politicians. This decision caused disappearance of symbolic names such as Sindh, Punjab etc. and promoted the domination of Urdu language and culture of Urdu-speaking ashraf. During this period Urdu was medium of instruction in government schools and English was taught as a compulsory subject. Mansoor (1993) reports that in 1959 a commission was set up to explore language issues in Pakistan. The commission stated that Urdu and Bengali should be the mediums of instructions in secondary schools in the government schools. It was also predicted that after 15 years of time period, Urdu will be in position to be a medium of instruction at university level (p. 10). Besides, it was also planned that Urdu was to be introduced to be a medium of instruction from class 6 in Sindhi-medium schools in Sindh. Rehman (1996) says that this decision received a reaction from Sindhis and they succeeded in having some of them blocked.

Haque (1993) says 1971 is the time when East Pakistan divorced from West Pakistan and Bangladesh emerged as an independent nation. After separation of East Pakistan from West Pakistan, the language policies were simplified in a sense that the issue of Bengali disappeared. This period was ruled by Zulifqar Ali Bhutto who did not bring any change in language policy for some reasons. Rehman (1996) reports that Urdu was supported by 
Bhutto's political enemies for example, in Balochistan and NWFP, NAP-JUI ruling parties opted for Urdu to be the official language in 1972 and in Punjab the islamicists were more enthusiastic about Urdu for its affiliation with Muslim identity. Therefore, the 1973 constitution formulated by Bhutto's government clearly stated that:

Clause.1: The national language of Pakistan is Urdu and arrangements shall be made for its being used for official and other purposes within fifteen years from the commencing day.

Clause.2: Subject to clause (1) the English language may be used for official purposes until arrangements are made for its replacement by Urdu.

Rehman (1998) says that Bhutto too found Islam and Urdu useful as integrative symbols against threat of ethnic break up. Thus, no significant changes occurred in language policy during PPP government led by Zulfiqar Ali Bhutto.

This democratic government was overthrown by a military ruler-General Zia-ul-Haq in 1977. This was the third martial law government in the country. Haque (1993) states that this period witnessed a drastic change in language policy. Urdu was given much value and importance. Zia's 'islamization' policy attached higher value with Urdu and Islam. Mehboob (2002) mentions that 1978 Education policy advised English medium schools to shift either to Urdu or to another recognized provincial language in each province. Only one language was to be selected as a medium of instruction in each province. This policy placed other regional/ethnic groups at disadvantage who felt their languages to be marginalized. During this period, Urdu was imposed as the medium of instruction in all government schools from class 1 and English was introduced in class 6.

During this period, General Zia-ul-Haq denationalized all the institutes and promoted 'privatization'. Thus, the number of private schools increased. Rehman (1996) maintains that General Zia-ul-Haq allowed private schools to use English as medium of instruction. And, he was highly criticized for this dual policy and termed as 'hypocrite' by the parents. However, the government realized that this was bit hurry in language policy so they revised it after Urdu-only policy. The government allowed using English for science subjects and students were given choice to take their exams either in Urdu or English. General Zia-ul-Haq in airplane crash in 1988 and succeeded by PPP and PML-N governments which did not bring any change in language policy. However, Benazir Bhutto during her first government brought some change in policy. She gave schools the option to choose English as a medium of instruction in all subject from class 1and it was also proposed that English should be taught as an additional language from class 1 rather than being introduced in class 6 as a subject as noted by Mehboob (2002, p. 26). This decision was taken up immediately by Sindh and Punjab governments. They introduced English as subject at primary level.

Later in General Musharraf's government in 1999 English was considered as symbol of progress. It was due to the fact that General Parvez Musharaf's chief aim was to boost up economy and increase foreign investments. To achieve this goal, English was considered as a passport to enter the global market.

National Education Policy (2009) introduced English as a subject from class 1 besides Urdu and one regional language. English language was introduced as a medium of instruction for sciences and mathematics subjects. In the beginning there was choice of Urdu or English but after five years, the teaching of these subjects will be in English only (p.28). Thus, this policy emphasizes English and Urdu and a little focus on regional language is given. It is clear from the statement that from class IV, English should be used for medium of instruction of teaching science subjects and mathematics. Sindhi language which is the mother tongue of the people of Sindh is marginalized through state policy.

Sindhi is an Indo-Aryan language spoken in Sindh — the province of Pakistan. Bughio (2001, p.30) mentions that eight languages are spoken in Sindh. Sindhi is most common language spoken by $52.4 \%$. Urdu and Punjabi are the next most spoken with $22.6 \%$ and $7.7 \%$ respectively. Other languages include Balochi, Pashto, Saraiki, Brahui, and Hindko. Rehman (1998) says that on the eve of partition, the position of Sindhi language was strong. Sindhi was taught as a subject at various levels in educational institutes. It was a medium of instruction in schools and also promoted in the university. Besides, Sindhi language was also used at low level of administration, judiciary and journalism. Rehman (ibid) says that anybody who learned Sindhi could get jobs easily. This was the time when Sindhi language enjoyed high status in the country. This position was enjoyed by Bengali and Sindhi only among all other indigenous languages.

Rehman (2002) maintains that the coming of Urdu-speaking Mohajirs from India to Sindh challenged the privileged position of Sindi language. The settlement of Urdu speaking Mohajirs in different parts of Sindh including Karachi, Hyderabad, Sukkur and other parts had very serious effect on population of Sind in terms of language, culture and politics. Sindh came be divided into: Sindhis and Mohajirs. Urdu language started 
replacing Sindhi language. Urdu due to its affiliation with 'Islamic' identity attained the recognition. This created a tension between Sindhis and Mohajirs. The tension between the two communities, Sindhis and Mohajirs on linguistic and cultural grounds so tightened that it led to language riots twice: one in January 1971 and other in July 1972. However, in the course of power struggle for the linguistic supremacy by one community or the other, Sindhi language has lost its utilitarian value as it enjoyed before partition.

\section{Methodology}

The study is qualitative in nature. Qualitative research involves the collection of extensive narrative data in order to gain insights into the phenomenon of interest; data analysis includes the coding of data and production of narratives or descriptions. Ian Dey (1993) proposes that 'Qualitative Research' has become a fashionable term which can be used for any method other than survey. It includes participant (and non-participant) observation, unstructured interviewing, group interviewing, the collection of documentary materials and the like.

\subsection{Data Collection Source \& Analysis}

The data comes from two sources: interviews and NEP (2009) along with ASER reports (2012, 2013, and 2014). A thorough investigation of National Education Policy and ASER reports was done in order to see the status of languages in the country and the consequence that overall language policy has had on Sindhi language teaching in Sindh Pakistan. ASER reports were quite useful to show the Sindhi literacy skills which can be understood in relation to dominant languages in education sector. Additionally, the interview was also taken as a supplementary data. Interview data was qualitatively analyzed using content analysis. Creswell (2008) is of the view that content analysis helps the researchers to divide descriptive data into categories and themes.

\subsection{Sampling \& Participants of the Study}

The study used purposive sampling to recruit the participants for the study. The purposes sampling helps the researcher to select the participants based on his/her knowledge and experiences which serve the purpose (Monette, Sullivan, \& Dijong, 2011). Five teachers $(n=5)$ aged between 25 and 35 were selected for in-depth semi-structured interviews. The teachers were selected from middle class and elite schools of Hyderabad, Sindh so that variation in responses could be obtained on the issue.

\section{Results of the Study}

The findings of the study are presented in two parts. The first part presents analysis of NEP (2009) and ASER Reports $(2012,2013$, and 2014) and the second part discusses results of the interview. NEP (2009) clearly states that the teaching of science and mathematics subjects will use English/or Urdu/regional official language as a medium of instruction for five years. Later, it will be purely in English. This statement disadvantages Sindhi language in Sindh province. The data coming from National Educational Policy (2009) marginalizes Sindhi language as a medium of instruction in Sindh. All science subjects are compulsorily to be taught in English language.

The language policy has had much effect on learning competencies of students in Sindh. It is reported in ASER (2013) survey that children have very low competencies in indigenous languages. Urdu/Sindhi/Pashto reading and numeracy skills of children in rural and urban Pakistan are low. This is different in case of English where students are able to read texts in English language. This shows that English is dominantly going better among students than other languages. The situation still remains same. ASER (2014) reports that the global education has failed to address the issues of equality in education in relation to wealth, gender, language, disability and other markers of disadvantage. In Sindh, there exist inequality in many factors language and gender being on top.

Such consequences are the result of power involved in determining the position of languages. Bourdieu (1991) cited in Tamim (2014) says language policy is capable of reinforcing the dominance of privileged groups which is mediated through educational institutes. Besides, language can be taken as important source of discrimination within education which is made possible through power structure. This is true in terms of Sindhi language. Sindhi language is facing double-challenge: one due to national policies and other due to intra-provincial division of Sindhi and Urdu speaking Mohajirs.

\subsection{Interview Findings}

Besides, the interview data also presents interesting responses on status of Sindhi language teaching in Sindh Pakistan which has highly come under attack by the dominant languages in the country. The questions asked during interviews are attached in appendix.1. One of the participants (P1) commenting on language policy said that: 
"Whatever the policy is, the fact is that Sindhi language and other regional languages are under threat. And, evidence for that is a number of young Sindhi students who are not able to read and write in their mother tongue."

He further said that:

"The school I am working in teaches Sindhi language from class 3 whereas Urdu is compulsory subject from Nursery class."

Another participant (P2) commented that:

"The school I am working in teaches Sindhi language from class-4 onwards. All the subjects are written in English. Urdu is taught as a subject from class one. As far as, the medium of instruction is concerned, English is more emphasized in premises of School. If somebody does not speak English, s/he is fined some amount of rupees. In some cases, Urdu can substitute English. As a result, Sindh has lost its place in school resulting in incompetency among students to be able to write or read."

A participant (P3) from low-paid private schools said that:

"We offer Sindhi as subject from class Nursery. However, in reading and writing are less focused. Students are encouraged to speak, write and read English. This has affected overall ability of students in their mother tongue, that is, Sindhi language."

In addition, P3 commenting on whether English and Urdu languages are a threat to Sindhi language teaching said that:

"In present situation, English and Urdu are the most dominant languages and thus, given more priority over Sindhi language. Sindhi is losing its historical status and if such language policy continues, Sindhi language will suffer a lot."

In line with the same discourse, other two participants (P4 \& P5) also said the same thing regarding status of Sindhi language in Pakistan. For example, P4 commented that:

"Sindhi is taught as a subject from beginning in school where I teach, but very honestly telling you that not much importance is being given to develop students' language skills in Sindhi language. Only the textbook of Sindhi language is followed which is completed in due time without caring whether students develop their language skills or not."

The participant P5 who taught at middle class private school said that:

"The issue with the low status of Sindh language is its market value. Today, Sindhi holds no more status as it enjoyed in the past. That's why learners don't consider it as important as English and Urdu."

All teachers belonging to different private schools showed concern regarding the status of Sindh language in schools. English and Urdu languages for their market value are being learnt, promoted and encouraged. The teachers believed that English and Urdu languages are a threat to Sindhi Language teaching in Sindh Pakistan and due to this phenomenon, the status of Sindhi language is under attack. The students are not developing their competencies in Sindhi language which affects the existence of Sindhi language as a whole. This results from language policy in Pakistan.

\section{Discussion \& Conclusion}

The issue of language is never isolated. It has to be studied in relation to power structure. The politics is actively engaged in determining the status of languages Pakistan. Since 1947, English and Urdu have attained higher status while the indigenous languages in the county are affected. Sindhi language though in the pre-partition era had utilitarian value but lost the same after making of Pakistan. The educational policies more focused on use of English and Urdu in all domains of power including education. And, the coming of Urdu-speaking Mohajirs in Sindh also appeared as a pressure group for Sindhis. As a result of this, Sindhi language has lost its value. The private schools have stopped teaching Sindhi language at lower level. English and Urdu are dominant language in educational institutes. Somebody who speaks English is looked upon down. This position requires the government officials to reconsider the status of indigenous languages and attach a certain utilitarian value with them so that these languages must be preserved as human most important heritage. Pakistan is a multilingual country. Giving status to only two languages namely English and Urdu creates a problem for other indigenous languages. Sindhi is one of seven major languages in Pakistan. Due to inappropriate language policy, Sindhi is at disadvantage. The government needs to devise a sensible language policy in which all local languages may be given due placement in local contexts and their education. Sindhi must be made the medium of instruction in all 
schools till secondary level and the curriculum should be revised and turned into Sindhi language. This is the only way we can preserve Sindhi language teaching which has a history of more than four thousand years.

\section{References}

ASER (2012): Annual Status of Education Report, Pratham.

ASER (2013): Annual Status of Education Report, Pratham.

ASER (2014): Annual Status of Education Report, Pratham.

Baumgardner, R. J. (1990). The indigenization of English in Pakistan. English Today, 6(1), 59-65. https://doi.org/10.1017/S0266078400004545

Bughio, Q. (2001). A Comparative Sociolinguistic Study of Rural and Urban Sindhi. Lincom Publishers.

Creswell, J. W. (2008). Qualitative Inquiry \& Research Design (3rd ed.). Sage Publication.

Dey, I. (1993). Qualitative Data Analysis. London and New York: Routledge Taylor and Francis Group. https://doi.org/10.4324/9780203412497

Edwards, J. (2009). Language \& Identity: An Introduction. Cambridge University Press. https://doi.org/10.1017/CBO9780511809842

Errington (2008). Linguistics in colonial world: A story of language, meaning and power. Blackwell Publishing.

Haque, A. (1993). The Position and Status of English in Pakistan. In 'The English Language in Pakistan.'

Mahboob, A. (2002). No English, No Future: Language Policy in Pakistan in Political Independence with linguistic servitude. In S. Obeng \& B. Hartford (Eds.), The Politics about languages in the Developing world (pp. 15-39). New York: Nova Science Publishers.

Manan, S. A., Dumanig, F. P., \& David, M. K. (2017). The English-medium fever in Pakistan: Analyzing policy, perceptions and practices through additive bi/multilingual education lens. International Journal of Bilingual Education and Bilingualism, 20(6), 736-752. https://doi.org/10.1080/13670050.2015.1080659

Mansoor, S. (1993). Language Planning in Higher Education: Issues of Access \& Equity. The Lahore Journal of Economics, 8(2).

Mustafa, Z. (2011). Tyranny of language in education, the problems and its solutions. Karachi: Ushba Publishing International.

NEP (2009). Proposals for a new education policy. Islamabad. Ministry of Education, Government of Pakistan.

Pathan, H. (2012). A longitudinal Study of Pakistani University Students' Motivation for Learning English. Unpublished PhD Thesis. Retrieved from http://theses.gla.ac.uk/4534/1/2012PathanPhD.pdf

Philipson, R. (1992). Linguistic Imperialism: Oxford University Press.

Rahman, T. (1998). Language Teaching Policies in Pakistan. Sustainable Development Policy Institute.

Rahman, T. (2007). The role of English in Pakistan with special reference to tolerance and militancy. In A. Tsui \& J. W. Tollefson (Eds.), Language policy, culture and identity in Asian contexts (pp. 219-239). Mahwah, NJ: Lawrence Erlbaum.

Rahman, T. (2010). Language policy, identity, and religion: Aspects of the civilization of the Muslims of Pakistan and North India (2nd ed.). Islamabad: National Institute of Pakistan Studies, Quaid-i-Azam University.

Rahman. (1996). Language \& Politics in Pakistan. Oxford University Press: Karachi.

Rahman. (2002). Language, Ideology \& Power: Language Learning among the Muslims of Pakistan and North India. Oxford University Press: Karachi.

Shah, S. W. A., \& Pathan, H. (2016). Representation of Western Culture in O' level English Language Textbooks. English Language Forum (ELF), 18.

Whiteley, W. (1983). Sociolinguistic Surveys at the National Level. In C. Kennedy (Ed.), Language Planning and Language Education (pp. 68-79). London: George Allen \& Unwin. 


\section{Copyrights}

Copyright for this article is retained by the author, with first publication rights granted to the journal.

This is an open-access article distributed under the terms and conditions of the Creative Commons Attribution license (http://creativecommons.org/licenses/by/4.0/). 